\title{
The Relation between the Eruption of the Deciduous Teeth and the Development and Growth of the Child
}

\author{
Sulafa Khair Al-Deen Banoosh \\ University of Tkirit, College of Dentistry, Department of Basic Sciences, Iraq \\ sulafa.khairy@yahoo.com
}

\begin{tabular}{l}
\hline ARTICLE INFO \\
\hline Submission date: 4/2/2019 \\
Acceptance date: 4/3/2019 \\
Publication date: 10/3/2019 \\
\hline
\end{tabular}

\begin{abstract}
This article aimed to find any relation between the eruption of the deciduous teeth and the development and growth of the child. This study included 77 children, aged between (1-2) years old all examined orally for any deciduous teeth eruption and record any delayed case, the parents of child answered 30 questions about the children's development.

The results of this study shown that there were no significant differences $(\mathrm{P}<0.05)$ between the teething (eruption of teeth) and the five developmental domains. Delayed teething was seen more among those with normal gross motor, and among those with delayed fine motor (statistically significant at 0.5 level). No relation between the eruption of the teeth and the development of the child and the teething time might be affected by local causes more than the systemic cause; these results need more researches and studies to prove these facts.
\end{abstract}

Key words: Teething, Eruption of teeth, Deciduous teeth, Primary teeth child.

\section{1- Introduction}

Growth can be defined as an increasing in the size of an individual due to the increases in number and diameter of the cells, while development shows child functional ripening. Growth and development are not corresponding words, but instead they are studied at the same time. The growth manner in a child should be joined with an assessment of the development to get an idea of the kid's execution when all is said in done advancement. Development and growth begin in pregnancy and end at ripening. They are interesting characteristics of kids and any postponement in this system at any period can achieve alteration of development or possible development[1].

Literatures contain typical theories illustrate the general development and growth like biologic, psychological and social effects [2].

In addition, more accurate model has been developed due to the promote in molecular biology, social and genetic sciences which are the ecobio- development that illuminates how ecology (social and physical environments) in the period of the childhood effect biologic events to give last health outcome [3]. 
Noticing the kid's growth give important information and indicator of child health[2].

Development delayed is an expressive term used when a child's development is late or deferred in at least one category when compared with other kids. While international development delay is the delay that happen in more than one domain. These differing settings of development consist of:

- Gross motor development; how children move, creep, sit, stand or walk.

- Fine motor development: how kids control objects and utilize their hands for exact fine movement and plays.

- Communication: how kids transport, understand and utilize language.

- Problem solving: how kids understand, think and learn.

- Social and emotional development: how kids interrelate with other children and make growing independence [4].

Caretakers end up wary of deferred when the kid doesn't achieve a few or the most common of the points of a situation (signs) at the normal age [4].

The first site of teeth erupted are the deciduous teeth, which also called the primary teeth, they grow and develop during the embryonic stage, they continue growing after birth until they appear in the oral cavity at 4 months [5].

The ages at which the primary teeth erupt are of great significance in relation to growth and development of the child. Most parents consider tooth eruption an important event in the child's development; hence, they often are anxious about timing and the sequence of eruption [6].

The delay in eruption of teeth up to 12 months may be of little or no importance in health of the kids. The delay usually results from local factors such as path of eruption or inadequate space in the dental arch, or any oral infections. Ectopic positions or impaction mostly affected the wisdom teeth (third molars), second premolars, and canines, probably due to that, these teeth are the last teeth erupted. The general failed of teething is considered a rare condition, which may be related to many systemic reasons [7].

The aim of paper study is to discover a delayed eruption of teeth consider a sign of delay in the development of the child.

\section{2- Material and methods}

This work was conducted between March and June 2017 the agreement permission was done in Salahuddin Health Directorate and Tikrit primary human services care in Tikrit city before managing the kids. This center was chosen as an alternative to hospital to preclude the alignment that might be product from any severe disease that could interrupt the development rank or scoring presentation of children or the eruption of the teeth. The age of the children (1-2) years, after elimination of some records, 77 children met the criteria of the study and were included in it. Age and stages questionnaires third edition were used as a screen test for developmental delayed [8]. These questionnaires involve 30 main questions, divided into 6 questions for each of the 5 domains of the development (communication, gross motor, fine motor, problem 
solving and social or emotional development), to determine the eruption of the teeth the oral examination was done in a room with good light and using dental mirror.

The statistical analysis used Microsoft excel 2013, the p- value (0.5) indicated significance.

\section{3- Results}

Table (1) shows the Chi square between the teething and domain- specific developmental delay, the $\mathrm{p}$ - value show that there was a significant difference in or the gross motor and fine motor in normal teeth eruption time, the $\mathrm{p}$ - values $(0.2,0.04)$ respectively.

Table (1) distribution of domain- specific developmental delay, according to normal eruption of teeth or delayed

\begin{tabular}{|c|c|c|c|c|c|}
\hline \multirow{2}{*}{\multicolumn{2}{|c|}{ Domain }} & \multicolumn{2}{|c|}{ Teething } & \multirow{2}{*}{$\begin{array}{c}\text { Chi } \\
\text { square }\end{array}$} & \multirow[t]{2}{*}{ p-value } \\
\hline & & Delayed & Normal & & \\
\hline \multirow[t]{2}{*}{ Communication } & Normal & 22 & 51 & \multirow{2}{*}{0.478} & \multirow{2}{*}{0.82} \\
\hline & Delayed & 1 & 3 & & \\
\hline \multirow[t]{2}{*}{ Gross motor } & Normal & 22 & 39 & \multirow{2}{*}{5.379} & \multirow{2}{*}{$* 0.2$} \\
\hline & Delayed & 1 & 15 & & \\
\hline \multirow[t]{2}{*}{ Fine motor } & Normal & 8 & 46 & \multirow{2}{*}{3.906} & \multirow{2}{*}{$* 0.04$} \\
\hline & Delayed & 15 & 8 & & \\
\hline \multirow[t]{2}{*}{ Problem solving } & Normal & 3 & 43 & \multirow{2}{*}{0.582} & \multirow{2}{*}{0.44} \\
\hline & Delayed & 20 & 11 & & \\
\hline \multirow[t]{2}{*}{ Social/emotional } & Normal & 4 & 50 & \multirow{2}{*}{1.72} & \multirow{2}{*}{0.18} \\
\hline & Delayed & 19 & 4 & & \\
\hline
\end{tabular}

* Delayed teething was seen more among those with normal gross motor, and among those- with delayed fine motor (statistically significant at 0.5 level)

\section{4- Discussion}

Teething is defined as the axial movement of the tooth from non-functional location in the jaws' bone to its functional occlusion. Yet, eruption is often used to express the moment of appearance of the teeth in the oral cavity. The ordinary eruption of primary and permanent teeth in the oral cavity make happen a wide chronological age range. Ethnic, racial, sexual, and specific reasons can affect eruption and are frequently considered in defining the ideals eruption. [9] The time of eruption (teething) varies between children. It can be very early in some kids and late in other, normally the teething time started at age 4 months until the first one year [10].

On the other hand, research and studies have been carried out all around the world in growth and development of children, the relationship between child growth and development with the time of teeth eruption is still considered a modern subject, which is still few and far. The delay in eruption of teeth may be the main or individual index of local or systemic pathology [11]. 
In this study, no association was found between the time of eruption of the first deciduous teeth and domain- specific developmental delay, that make local or systemic and even genetic effects influence the time of eruption more than the delayed in growth and development of the baby [10]. This result disagrees with (Udhya et al) how consider the delay teething in children who they had autism (development delay) due to phenytoin-induced gingival hyperplasia. Phenytoin is commonly prescribed for people with autism.

\section{5- Conclusion}

The time eruption of teeth not related to the degree of the development of the child and not considered a sign for the delay in development and growth of the kid. Generally, these results may be due to the small samples that marked which need more researches to improve it.

\section{Ethical Approval}

The Ethical Committees of the journal and hospital approved the experimental work. Privacy was maintained regarding patient data.

\section{Conflict of Interests.}

There are non-conflicts of interest.

\section{References}

1- A. Parthasarathy, IAP Textbook of pediatrics. Jaypee Brothers, Medical Publishers Pvt. Limited, 2019.

2- $\quad$ R. Kliegman, B. Stanton, J. W. St. Geme, N. F. Schor, R. E. Behrman, and W. E. Nelson, "Nelson textbook of pediatrics." 2016.

3- A. K. B. Al-Ayoobi, "Epidemiology of Developmental Delay among Children under Two Years of Age Attending Primary Health Care Centers In Tikrit City", M. Sc. thesis, College of medicine, University of Tikrit, 2018.

4- A. Parthasarathy, IAP Textbook of pediatrics. Jaypee Brothers, Medical Publishers Pvt. Limited, 2019.

5- S. J. Nelson, Wheeler's Dental Anatomy, Physiology and Occlusion-E-Book. Elsevier Health Sciences, 2014.

6- N. M. Al-Jasser and L. L. Bello, "Time of Eruption of Primary Dentitionin Children from Saudi Arabia," J Contemp Dent Pr., pp. 65-75, 2003.

7- S. Petti and C. Scully, "Polyphenols, oral health and disease: A review," J. Dent., vol. 37, no. 6, pp. 413-423, 2009.

8- J. Squires, D. D. Bricker, and E. Twombly, Ages \& stages questionnaires. Paul H. Brookes Baltimore, MD, USA:, 2009.

9- L. Suri, E. Gagari, and H. Vastardis, "Delayed tooth eruption: pathogenesis, diagnosis, and treatment. A literature review," Am. J. Orthod. Dentofac. Orthop., vol. 126, no. 4, pp. 432-445, 2004. 
10- R. M. Viscardi, E. Romberg, and R. Abrams, "Delayed primary tooth eruption in premature infants: relationship to neonatal factors," Pediatr. Dent., vol. 16, p. 23, 1994.

11- F. C. Peedikayil, "Delayed Tooth Eruption," e-Journal Dent., vol. 1, no. 4, 2011.

12- J. Udhya, M. M. Varadharaja, and J. Parthiban, "Autism disorder (AD): an updated review for paediatric dentists," J. Clin. diagnostic Res. JCDR, vol. 8, no. 2, p. 275, 2014.

الخلاصة

تهلف هذه الدقالة إلى إيجاد أي علاقة بين اندلاع الأسنان اللبنية وتطور ونمو الطفل. المواد والطرق؛ تم إدراج 77 طفلاً في هذه الدراسة،

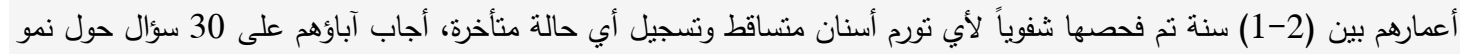

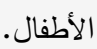

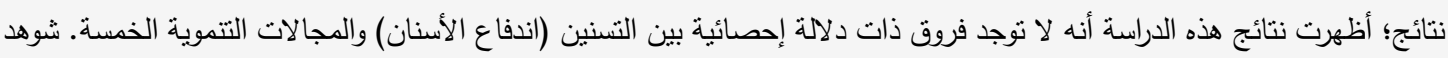

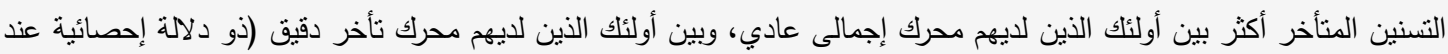

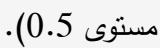
استنتاجات. لا علاقة بين اندلاع الأسنان وتطور الطفل ووقت النسنين قد تتأثر بالأسباب المحلية أكثر من السبب النظامي ، هذه الننائج

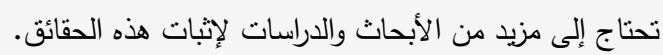
الكلمات الدالة؛ الاندفاع ، التنسين ، النمو ، النمو ، الأسنان اللبنية. 